\title{
Decision making for others: The case of Loss Aversion
}

\author{
By SASCHA C. FÜLLBRUNN ${ }^{1}$ and WOLFGANG J. LUHAN ${ }^{2}$
}

\begin{abstract}
Risky decisions are at the core of economic theory. While many of these decisions are taken on behalf of others rather than for oneself, the existing literature finds mixed results on whether people take more or less risk for others then for themselves. Recent studies suggest that taking decisions for others reduces loss aversion, thereby increasing risk taking on behalf of others. To test this, we elicit loss aversion in three treatments: making risky decisions for oneself, for one other subject, or for the decision maker and another person combined. We find a clear treatment effect when making decisions for others but not when making decisions for both.
\end{abstract}

JEL: C9, D3, D8

Keywords: decision making for others; risk taking; loss aversion; experiment

\footnotetext{
${ }^{1}$ Radboud University, Institute for Management Research, Department of Economics, Thomas van Aquinostraat 5.1.15, 6525 GD Nijmegen, The Netherlands (s.fullbrunn@fm.ru.nl). The funding is from: Institute for Management Research

${ }^{2}$ University of Portsmouth, Portsmouth Business School, Richmond Building, Portland Street, Portsmouth PO1 3DE, United Kingdom, (wolfgang.luhan@port.ac.uk)
} 


\section{Introduction}

Standard decision theory mainly considers individual decision processes in which the decision maker is the only affected person by his decisions. However, the majority of financial decisions affects not only the decision maker himself but also others, e.g. investments on financial markets usually have to be made via a money manager who decides on his client's behalf. Andersson et al. (2014) argue that loss aversion plays a role when making risky decision for others. They hypothesize that people take higher risks for others due to a reduced loss aversion. The theoretical background stems from the dual-process model of decision making (Kahneman, 2003; Rustichini, 2008) in which decisions taken for others differ in the weighting of emotional and cognitive components involved. Using data from an online experiment with a large number of subjects randomly drawn from the general Danish population, Andersson et al. (2014) conclude that loss aversion indeed is reduced when subjects make decisions for others. The conclusion is derived from a structural model assuming a constant relative risk-aversion utility function with a kink at zero. However, nonparametric tests cannot reject the null hypothesis of equal loss aversion levels when comparing decision making for self or for others. Hence, it is unclear whether a treatment effect exists when considering other model specifications. In particular the CRRA model has been shown to have only a very limited predictive power regarding the observed behavior in experiments (Friedman et al., 2014). Instead, Vieider et al. (2016) consider a broader experimental setup making use of structural models based on prospect theory (Tversky $\&$ Kahneman, 1992) including probability weighting functions. Only under specifications identical to those of Andersson et al. (2014), Vieider et al. (2016) are able to replicate the result concerning the effect of loss aversion. For other specifications, however, they fail to find significant differences. Vieider et al. (2016) conclude that a clear loss aversion affect cannot be verified as it depends crucially on the definition adopted in the setup of the structural model. Hence, the literature on decision making for others has so far not provided convincing evidence for the loss aversion effect (see Füllbrunn and Luhan (2015) for a general overview).

We aim to clarify this issue. In contrast to the above mentioned papers, we directly elicit loss aversion levels using an established procedure discussed in detail by Gächter et al. (2010) (see references and proofs therein). In a between-subjects design, we implement three treatments reflecting Andersson et al. (2014) and Vieider et al. (2016). In treatment Self, each subject makes a decision for herself. In Aligned, each subject makes the same decision for herself AND for a randomly drawn subject in the laboratory. In Others, each subject makes a decision for a randomly drawn participant in the laboratory without consequences for the decision maker. If loss aversion plays a role, then the loss aversion level should be higher in Self than in either Aligned or in Others. 
Our results show that loss aversion levels are indeed higher in Self than in Others. We do not find such an effect comparing Self and Aligned though.

\section{Procedure}

In line with Gächter et al. (2010), individuals decided for each of six lotteries whether they want to accept or reject it. The price in case of a success is fixed at six euro in each lottery, the loss varied between two and seven euro. At the end of the experiment, one lottery was randomly determined for the payoff. In a between-subjects design, we consider the three treatments Self, Aligned, and Others as described above. Figure 1 reproduces the decisions for all treatments. The only treatment difference is the wording, i.e. “...you win (lose)..." in Self, “...you and the other participant win (lose)..." in Aligned, and "...the other participant wins (loses)..." in Others.

\begin{tabular}{|c|c|c|c|}
\hline \multicolumn{2}{|c|}{ Lottery } & \multirow{2}{*}{$\begin{array}{c}\text { Accept } \\
\mathrm{O}\end{array}$} & \multirow{2}{*}{\begin{tabular}{|c} 
Reject \\
$\mathrm{O}$
\end{tabular}} \\
\hline$\# 1$ & $\begin{array}{l}\text { If the coin turns up tails, you lose (you and the other participant lose/the other participant loses) } 2 \text { Euro; } \\
\text { if the coin turns up heads, you win (you and the other participant win/the other participant wins } 6 \text { Euro. }\end{array}$ & & \\
\hline$\# 2$ & $\begin{array}{l}\text { If the coin turns up tails, you lose (you and the other participant lose/the other participant loses) } 3 \text { Euro; } \\
\text { if the coin turns up heads, you win (you and the other participant win/the other participant wins } 6 \text { Euro. }\end{array}$ & $\mathrm{O}$ & $\mathrm{O}$ \\
\hline$\# 3$ & $\begin{array}{l}\text { If the coin turns up tails, you lose (you and the other participant lose/the other participant loses) } 4 \text { Euro; } \\
\text { if the coin turns up heads, you win (you and the other participant win/the other participant wins } 6 \text { Euro. }\end{array}$ & $\mathrm{O}$ & $\mathrm{O}$ \\
\hline$\# 4$ & $\begin{array}{l}\text { If the coin turns up tails, you lose (you and the other participant lose/the other participant loses) } 5 \text { Euro; } \\
\text { if the coin turns up heads, you win (you and the other participant win/the other participant wins } 6 \text { Euro. }\end{array}$ & $\mathrm{O}$ & $\mathrm{O}$ \\
\hline$\# 5$ & $\begin{array}{l}\text { If the coin turns up tails, you lose (you and the other participant lose/the other participant loses) } 6 \text { Euro; } \\
\text { if the coin turns up heads, you win (you and the other participant win/the other participant wins } 6 \text { Euro. }\end{array}$ & $\mathrm{O}$ & $\mathrm{O}$ \\
\hline \#6 & $\begin{array}{l}\text { If the coin turns up tails, you lose (you and the other participant lose/the other participant loses) } 7 \text { Euro; } \\
\text { if the coin turns up heads, you win (you and the other participant win/the other participant wins } 6 \text { Euro. }\end{array}$ & $\mathrm{O}$ & $\mathrm{O}$ \\
\hline
\end{tabular}

\section{FIGURE 1. TASK - ACCEPT OR REJECT LOTTERIES}

We implemented the experiment as follows. Upon arrival, the participants received a one page instruction including the receipt already featuring a ten euro show-up fee. ${ }^{3}$ The experimenter read out the instructions aloud and asked participants to fill in their name, the date, and also their signature on the receipt. The participants turned the page to find treatment specific instructions. The program was started and the decision screen appeared. Now the experimenter read the second page of the instructions and asked for questions. Due to the simple instructions, almost no questions were asked and participants started to enter their decisions on screen. After making their decisions, the participants filled in a questionnaire eliciting demographics, risk aversion (Dohmen et al., 2011) and a social responsibility score (Berkowitz \& Lutterman, 1968). ${ }^{4}$ After the questionnaire, the participants learned the lottery-result and their payoff

\footnotetext{
3 The full paper and on-screen instructions can be found in the appendix.

4 Find details in Füllbrunn and Luhan (2015).
} 
(positive or negative) from the experiment. Participants were paid privately and in cash before leaving the laboratory.

In Aligned, two participants were matched after the decision stage and the program randomly determined one decision to be implemented for both participants. In Others, the software randomly chose participant $i$ to make the decision for participant $j, j$ to make the decision for $k$ and so on. Matching was done anonymously and no interaction took place between the participants.

We ran the experiments at the NSM Decision Lab at Radboud University in Nijmegen (NL) and at the strateGiX lab at Rhine Waal University of Applied Science in Kleve (D) right across the border. In Nijmegen, subjects were recruited using ORSEE (Greiner, 2015) while in Kleve subject were recruited using hroot (Bock et al., 2014). We programmed the experiment in z-Tree (Fischbacher, 2007). We ran several sessions yielding a total of 53 decisions (33 NL/20 D) in Self, 49 decisions (29/20) in Aligned, and 40 decisions (21/19) in Others. ${ }^{5}$ Each session lasted about 20 minutes and the average earnings were 10.32 euro (SD 3.62). As we find no significant difference across subject pools after treatment comparisons (see appendix), we merge the subject pools in the upcoming analysis.

\section{Results}

In line with the literature (e.g. Gächter et al., 2010), we consider only subjects with monotonic acceptance decisions ( 88 percent). The loss aversion proxy is thus the number of rejected lotteries ( $7=$ reject all, $6=$ accept only $\# 1,5=$ accept only $\# 1$ and \#2, .., 1=accept all) with 7 meaning highly loss averse. Figure 2 displays violin plots together with $\mathrm{p}$-values from non-parametric tests.

${ }^{5}$ Differences are due to no-shows. 


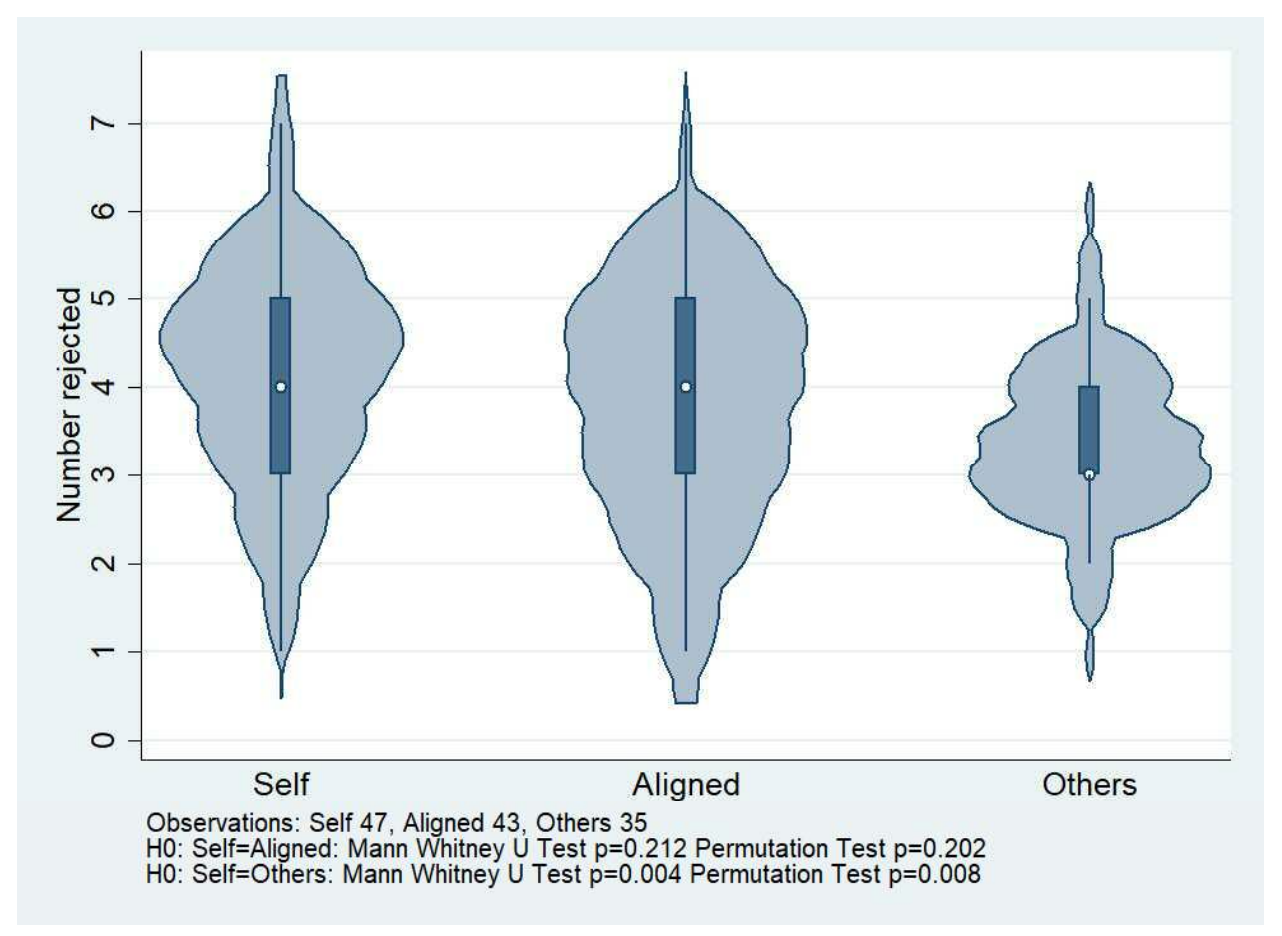

Figure 2. Violin Plots - Number of REJECTED LOtTERIES

While the figure indicates no difference between Self and Aligned (same median, same interquartile ranges, almost similar density functions) it indicates a clear difference between Self and Others (lower median, lower 75\% quartile, right skewed density function). The two tests show no difference between $\mathrm{Self}$ and Aligned $(\mathrm{p}>0.2)$ but a significant difference between Self and Others $(\mathrm{p}<0.001$, Post-hoc power 0.71 using G*Power from Faul et al., (2007)), i.e. the number rejected is lower in Others than in Self.

The Poisson regressions in Table 1, with the number of lotteries rejected as the dependent variable, two treatment dummies and additional controls as independent variables, support the results from the nonparametric tests (for details see appendix). The Others dummy is significantly negative in the model with and without controls; subjects in Others reject on average one lottery less than in Self. In contrast, the dummy for treatment Aligned is not significant.

\section{TABLE 1 POISSON REGRESSION: NUMBER OF REJECTED LOTTERIES}

\begin{tabular}{cccccccc}
\hline & Aligned & Others & Constant & $\mathrm{N}$ & Wald $\chi^{2}$ & Prob. $<\chi^{2}$ & Controls \\
\hline Model 1 & -0.095 & -0.20 & 1.43 & 125 & 8.0133 & 0.0182 & No \\
& $(0.070)$ & $(0.073)^{* *}$ & $(0.044)^{* * *}$ & & & & \\
Model 2 & -0.093 & -0.20 & 1.55 & 125 & 75.4095 & $<0.0001$ & Yes \\
& $(0.055)$ & $(0.068)^{* *}$ & $(0.03)^{* * *}$ & & & &
\end{tabular}

Notes: Poisson regressions with the number of rejected lotteries as dependent variable. Main variables of interests are the treatment dummies Aligned and Others. Controls include a location dummy (Nijmegen, Kleve), a dummy for economics students, a female dummy, age, the social responsibility score, and general risk. Standard errors in parentheses. ${ }^{* *} \mathrm{p}<0.01,{ }^{* *} \mathrm{p}<0.05,{ }^{*} \mathrm{p}<0.1$. 
Assuming cumulative prospect theory, the implied loss aversion for each loss level $L$ is $\lambda=$ $\omega^{+}(0.5) / \omega^{-}(0.5) \times v^{+}(6) / v^{-}(L)$ with the weighting function $\omega$ and the value function $v$ in the gain $(+)$ and loss (-) domain. In line with Gächter et al. (2010), we take into account different benchmarks for these functions, i.e. $\omega^{+}(0.5) / \omega^{-}(0.5)=1$ or $\omega^{+}(0.5) / \omega^{-}(0.5)=0.86$ for the weighing functions, and $(\alpha, \beta)=(1,1)$ or $(\alpha, \beta)=(0.95,0.92)$ for sensitivity. Applying these benchmarks yield similar lambdas for Self and Aligned (Median for the four parameter constellations: 1.50, 1.53, 1.30, and 1.32) which are quite close to Gächter et al. (2010). However, the lambdas are significantly lower in Others $(1.20,1.25$, 1.04, and 1.08) than in Self, indicating a lower loss aversion for others (see appendix for more details).

\section{Conclusion}

Using an established elicitation tool for loss aversion, we find clear evidence that decision makers show lower loss aversion when making decision for others than when making decision for themselves. However, this is true when making decision for others only, and not when payoffs are aligned. Our results are robust to changes of empirically observed prospect theory parameters.

Comparing to Andersson et al. (2014), in particular our Table 1 to their Table 2, we find lower loss aversion for others only when the decision bears no consequences for the decision maker. When payoffs are aligned, we find no difference in loss aversion. We mirror the findings of Vieider et al. (2016)-who only considered Aligned but not Others-in that there is no difference between Self and Aligned. These differences in the definition of 'decisions for others'-once including, once excluding the decision maker-appears to be the reason for the mixed results in the previous literature. Given our results, it would be interesting to see whether Vieider et al. (2016) with a richer set of structured estimations than Andersson et al. (2014) come to the same conclusion-the difference between Self and Others-when they use their experimental setup but with Others instead of with Aligned.

Our results indicate that responsibility for other people plays a limited role for the loss aversion in financial decisions as long as the decision maker bears the consequences as well. 


\section{References}

Andersson, O., Holm, H. J., Tyran, J.-R., \& Wengström, E. (2014). Deciding for Others Reduces Loss Aversion. Management Science, 2461(13), 0-38.

Berkowitz, L., \& Lutterman, K. G. (1968). The Traditional Socially Responsible Personality. The Public Opinion Quarterly, 32(2), 169-185.

Bock, O., Baetge, I., Nicklisch, A., Bocka, O., Baetgeb, I., \& Nicklisch, A. (2014). hroot: Hamburg Registration and Organization Online Tool. European Economic Review, 71, 117-120.

Dohmen, T., Falk, A., Huffman, D., Sunde, U., Jürgen, S., \& Wagner, G. G. (2011). Individual Risk Attitudes: Measurement, Determinants, and Behavioral Consequences, Journal of the European Economic Association, 9(3), 522-550.

Faul, F., Erdfelder, E., Lang, A.-G., \& Buchner, A. (2007). G*Power: A flexible statistical power analysis program for the social, behavioral, and biomedical sciences. Behavior Research Methods, 39(2), 175191.

Fischbacher, U. (2007). Z-Tree: Zurich toolbox for ready-made economic experiments. Experimental Economics, 10(2), 171-178.

Friedman, D., Isaac, R. M., James, D., \& Sunder, S. (2014). Risky Curves: On the Empirical Failure of Expected Utility. Routledge.

Füllbrunn, S. \& Luhan, W.J. (2015). Am I My Peer's Keeper? Social Responsibility in Financial Decision Making, NiCE Working Paper 15-03, Institute for Managemenet Research, Radboud University, The Netherlands

Gächter, S. ;, Johnson, E. J. ;, \& Herrmann, A. (2010). Individual-level loss aversion in riskless and risky choices. Cedex, (October), 26.

Greiner, B. (2015). Subject pool recruitment procedures: organizing experiments with ORSEE. Journal of the Economic Science Association, 1(1), 114-125.

Kahneman, D. (2003). A Perspective on Judgment and Choice: Mapping Bounded Rationality. American Psychologist, 58(9), 697-720.

Rustichini, A. (2008). Dual or unitary system? Two alternative models of decision making. Cognitive, Affective \& Behavioral Neuroscience, 8(4), 355-62.

Tversky, A., \& Kahneman, D. (1992). Advances in Prospect-Theory - Cumulative Representation of Uncertainty. Journal of Risk and Uncertainty, 5(4), 297-323.

Vieider, F. M., Villegas-Palacio, C., Martinsson, P., \& Mejía, M. (2016). Risk taking for oneself and others: A structural model approach. Economic Inquiry, 54(2), 879-894. 


\section{Appendix}

to Füllbrunn and Luhan - Decision making for others: The case of Loss Aversion

\section{$\underline{\text { Additional Tables and Tests }}$}

Appendix Table 1, shows the number of monotone observations used in the analysis (first number) and the number of total observations (second number). In total we use $125 / 142=88 \%$ of the observations (Gächter et al., 2010 use 91\%). The last two rows show p-values for tests comparing the two subject pools, i.e. testing the Null whether the subjects pool differ with respect to the number of rejected lotteries. The p-values indicate that we cannot reject the Null. Regressions below take the subject pool difference into account.

\begin{tabular}{lccc} 
& Self & Aligned & Others \\
\hline Obs. NL & $31 / 33$ & $29 / 29$ & $20 / 21$ \\
Obs. D & $19 / 20$ & $14 / 20$ & $15 / 19$ \\
\hline Obs. Total & $47 / 53$ & $43 / 49$ & $35 / 40$ \\
\hline Mann Whitney U test & 0.7090 & 0.6493 & 0.4849 \\
Permutation test & 0.7698 & 0.7092 & 0.4717 \\
\hline
\end{tabular}

APPENDIX TABLE 1 NuMBER OF OBSERVATIONS AND SUBJECT POOL COMPARISON 
Appendix Table 2 Poisson Regression (Details for Table 1), depicts detailed regression results related to Table 1 in the paper.

\begin{tabular}{lcc} 
& Model 1 & Model 2 \\
\hline Aligned & -0.095 & -0.093 \\
& $(0.070)$ & $(0.055)$ \\
Others & $-0.20^{* *}$ & $-0.20^{* *}$ \\
& $(0.073)$ & $(0.068)$ \\
Location & & -0.024 \\
& & $(0.065)$ \\
ECON & & 0.049 \\
& & $(0.049)$ \\
Female & & -0.068 \\
& & $(0.053)$ \\
Age & & -0.0017 \\
& & $(0.0095)$ \\
SRS & & $0.15^{*}$ \\
& & $(0.061)$ \\
Risk & & $-0.10^{* * *}$ \\
& & $(0.014)$ \\
Constant & $1.43^{* * *}$ & $1.55^{* * *}$ \\
& $(0.044)$ & $(0.30)$ \\
---------------------------------- \\
---- & & \\
No. Obs. & 125 & 125 \\
Wald $\chi^{2}$ & 8.01 & 75.41 \\
Prob $<\chi^{2}$ & 0.018 & $<0.001$ \\
\hline
\end{tabular}

ApPendiX TABLe 2 Poisson Regression (Details for Table 1) 
In Andersson et al. (2014), they run an analogue estimation in their table 2 and additionally provide a similar estimation for risk. For comparability, we do the same for the general risk measure (Dohmen et al., 2011). Using a simple OLS regression, we find no effect on risk as the treatment dummies are not significant. For risk, our results are in line with Andersson et al. (2014).

\begin{tabular}{ccc} 
& Model 1 & Model 2 \\
\hline Aligned & -0.032 & 0.045 \\
& $(0.41)$ & $(0.40)$ \\
Others & 0.055 & -0.14 \\
& $(0.42)$ & $(0.42)$ \\
Location & & -0.056 \\
& & $(0.42)$ \\
ECON & & 0.3 \\
& & $(0.37)$ \\
Female & & -1.22 \\
& & $(0.37)^{* * *}$ \\
Age & & 0.12 \\
& & $(0.047)^{*}$ \\
SRS & & 0.19 \\
& & $(0.38)$ \\
Constant & 5.66 & 2.9 \\
& $(0.26)$ & $(1.86)$ \\
\hline Obs. & 125 & 125 \\
$\mathrm{R}^{\wedge} 2$ & $<0.001$ & 0.123 \\
\hline
\end{tabular}

APPENDIX TABLE 3 RoBUSt OLS REgRESSION WITH GENERAL RiSK AS DEPENDENT VARIABLE (Details on independent variables see Table 1) 
Appendix Table 4 Acceptance rates of the different lotteries in the lottery choice task and implied $\lambda=\omega \times\left(\frac{6 \alpha}{L \beta}\right), \omega=w^{+}(0.5) / w^{-}(0.5)$ depicts implied loss aversion levels depending on four different models discussed in Gächter et al. (2010) with median levels provided for each of our three treatments and for their data for comparison. The results show quite nicely that our results in Self and Aligned do not differ to results in Gächter et al. (2010). However, the results in Others differ significantly to the results in Self.

\begin{tabular}{|c|c|c|c|c|c|}
\hline & & \multicolumn{4}{|c|}{ Implied Loss Aversion $(\lambda)$} \\
\hline & \multirow{4}{*}{$\begin{array}{c}\text { Implied } \\
\text { Accepted } \\
\text { Loss }\end{array}$} & (1) & (2) & (3) & (4) \\
\hline & & $\alpha=1$ & $\alpha=.95$ & $\alpha=1$ & $\alpha=95$ \\
\hline & & $\beta=1$ & $\beta=.92$ & $\beta=1$ & $\beta=.92$ \\
\hline & & $\omega=1$ & $\omega=1$ & $\omega=.86$ & $\omega=.86$ \\
\hline 7) Reject all lotteries & $<2$ & $>3$ & $>2.9$ & $>2.59$ & $>2.51$ \\
\hline 6) Accept $\# 1$, otherwise reject & 2 & 3 & 2.9 & 2.59 & 2.51 \\
\hline 5) Accept $\# 1$ to $\# 2$, otherwise reject & 3 & 2 & 2 & 1.73 & 1.73 \\
\hline 4) Accept $\# 1$ to $\# 3$, otherwise reject & 4 & 1.5 & 1.53 & 1.3 & 1.32 \\
\hline 3) Accept \#1 to \#4, otherwise reject & 5 & 1.2 & 1.25 & 1.04 & 1.08 \\
\hline 2) Accept $\# 1$ to $\# 5$, otherwise reject & 6 & 1 & 1.06 & 0.86 & 0.91 \\
\hline 1) Accept all & $\geq 7$ & $\leq 0.86$ & $\leq 0.92$ & $\leq 0.74$ & $\leq 0.79$ \\
\hline \multirow{4}{*}{ Median } & Self & 1.50 & 1.53 & 1.30 & 1.32 \\
\hline & Aligned & 1.50 & 1.53 & 1.30 & 1.32 \\
\hline & Others & 1.20 & 1.25 & 1.04 & 1.08 \\
\hline & GJH & 1.50 & 1.53 & 1.32 & 1.29 \\
\hline \multicolumn{2}{|l|}{$\begin{array}{l}\text { H0: Self }=\text { Aligned, p-values } \\
\text { Mann Whitney U Test/Permutation Test }\end{array}$} & $0.2115 / 0.2277$ & $0.2115 / 0.2201$ & $0.2115 / 0.2277$ & $0.2115 / 0.2209$ \\
\hline \multicolumn{2}{|l|}{$\begin{array}{l}\text { H0: Self }=\text { Others, } p \text {-values, } \\
\text { Mann Whitney U Test/Permutation Test }\end{array}$} & $0.0044 / 0.0144$ & $0.0044 / 0.0130$ & $0.0044 / 0.0136$ & $0.0044 / 0.0130$ \\
\hline
\end{tabular}

APPENDIX TABLE 4 ACCEPTANCE RATES OF THE DIFFERENT LOTTERIES IN THE LOTTERY CHOICE TASK AND IMPLIED $\lambda=\omega \times\left(\frac{6 \alpha}{L \beta}\right), \omega=w^{+}(0.5) / w^{-}(0.5)$ 
Appendix Table 5 shows results of simple OLS regressions for each of the four model benchmarks. As can be seen, the Others dummy is significant in all models while the Aligned dummy is not significant.

\begin{tabular}{|c|c|c|c|c|c|c|c|c|}
\hline & $3 a$ & $3 b$ & $4 a$ & $4 b$ & $5 \mathrm{a}$ & $5 b$ & $6 \mathrm{a}$ & $6 b$ \\
\hline \multirow[t]{2}{*}{ Aligned } & -0.14 & -0.16 & -0.13 & -0.15 & -0.12 & -0.14 & -0.11 & -0.13 \\
\hline & $(0.11)$ & $(0.094)$ & $(0.10)$ & $(0.087)$ & $(0.096)$ & $(0.082)$ & $(0.089)$ & $(0.075)$ \\
\hline \multirow[t]{2}{*}{ Others } & $-0.29^{*}$ & $-0.33^{* *}$ & $-0.27^{*}$ & $-0.31^{* *}$ & $-0.25^{*}$ & $-0.29^{* *}$ & $-0.23^{*}$ & $-0.27^{* *}$ \\
\hline & $(0.11)$ & $(0.10)$ & $(0.11)$ & $(0.093)$ & $(0.099)$ & $(0.087)$ & $(0.091)$ & $(0.081)$ \\
\hline \multirow[t]{2}{*}{ Location } & & -0.090 & & -0.081 & & -0.078 & & -0.070 \\
\hline & & $(0.10)$ & & $(0.093)$ & & $(0.087)$ & & $(0.080)$ \\
\hline \multirow[t]{2}{*}{$\mathrm{ECON}$} & & -0.042 & & -0.040 & & -0.037 & & -0.034 \\
\hline & & $(0.083)$ & & $(0.077)$ & & $(0.072)$ & & $(0.067)$ \\
\hline \multirow[t]{2}{*}{ Female } & & -0.089 & & -0.083 & & -0.077 & & -0.072 \\
\hline & & $(0.090)$ & & $(0.083)$ & & $(0.078)$ & & $(0.072)$ \\
\hline \multirow[t]{2}{*}{ Age } & & 0.0040 & & 0.0034 & & 0.0035 & & 0.0029 \\
\hline & & $(0.014)$ & & $(0.013)$ & & $(0.012)$ & & $(0.011)$ \\
\hline \multirow[t]{2}{*}{ SRS } & & $0.21^{*}$ & & $0.20^{*}$ & & $0.18^{*}$ & & $0.17^{*}$ \\
\hline & & $(0.087)$ & & $(0.081)$ & & $(0.075)$ & & $(0.070)$ \\
\hline \multirow[t]{2}{*}{ Risk } & & $-0.14^{* * *}$ & & $-0.13^{* * *}$ & & $-0.12^{* * *}$ & & $-0.12^{* * *}$ \\
\hline & & $(0.023)$ & & $(0.021)$ & & $(0.020)$ & & $(0.018)$ \\
\hline \multirow[t]{2}{*}{ Constant } & $1.70^{* * *}$ & $1.86^{* * *}$ & $1.71^{* * *}$ & $1.87^{* * *}$ & $1.47^{* * *}$ & $1.61^{* * *}$ & $1.48^{* * *}$ & $1.62^{* * *}$ \\
\hline & $(0.079)$ & $(0.41)$ & $(0.073)$ & $(0.38)$ & $(0.068)$ & $(0.36)$ & $(0.063)$ & $(0.33)$ \\
\hline No. Obs. & 125 & 125 & 125 & 125 & 125 & 125 & 125 & 125 \\
\hline Wald $\chi^{2}$ & 0.048 & 0.335 & 0.049 & 0.339 & 0.048 & 0.335 & 0.049 & 0.339 \\
\hline
\end{tabular}

APPENDIX TABLE 5 RoBUST OLS REgRESSIONS WITH IMPLIED LOSS AVERSION PARAMETERS AS DEPENDENT VARIABLE (Details on independent variables see Table 1) 


\title{
Instructions and Screenshots
}

First Page for each subject

\author{
Welcome to the experiment. \\ Do not talk to the other participants from now on. Switch off your mobile phone. Use only those \\ functions of the $P C$ that are necessary for the conduct of the experiment.
}

\section{INSTRUCTIONS}

The purpose of this experiment is to study decision behaviour. You will earn real money in this experiment. Your payment will be determined by your own decisions or by the decisions of other participants in this room, according to the rules below. We guarantee anonymity; neither the other participants nor the experimenter will find out which choices you have made, and earnings at the end of the experiment will be paid in private.

For participating in this experiment you receive a participation fee of $€ 10$. On your receipt below, this amount is inserted already. Please fill in Date, Name, and your Signature on the receipt now...

The experiment consists of one task and a short questionnaire. The whole procedure should not take longer than 20 minutes.

In the task you will have the chance to win or lose money in addition to the $€ 10$.

After you answered a short questionnaire your payment from the task will be shown at your screen. Please enter the amount in the second line on your receipt and calculate final earnings.

You will be called to the front desk individually. Please bring the small number card and the signed receipt with you. The payment will be in cash, private and anonymous.

Do you have any questions?

Then I will start the programme...

Radboud University

Thomas van Aquinestraat 5.0.51

Institute for Management Researcb

Postbus 9108, 6500 HK Nijmegen, Netherlands

\section{RECEIPT}

Receipt $\mathrm{Nr}$.

Hereby I confirm that I received from the project " $\mathrm{CF}_{15}$ " the amount of

10 Euro +1-

Euro $=$ Euro

for the participation in an experiment.

Nijmegen, Date

Name: Signature: 
Backside of instruction plus screenshot

Self

Have a look at your screen

You see six lotteries in which you can win or lose money. For each lottery, YOU have to decide whether you want to accept or reject the lottery.

If you accept the lottery, the computer flips a coin;

- if the coin shows heads, you receive 6 Euros in addition to your participation fee;

- if the coin shows tails, you lose a certain amount of your participation fee.

If you reject a lottery, no amount will be added (subtracted) to (from) your participation fee.

After you have clicked the button "CONFIRM YOUR CHOICES", the computer randomly picks one of the six lotteries for payoff. If you have chosen to accept this lottery, the computer flips the coin and your payments are determined as indicated on the screen.

Your payments will be shown after the questionnaire.

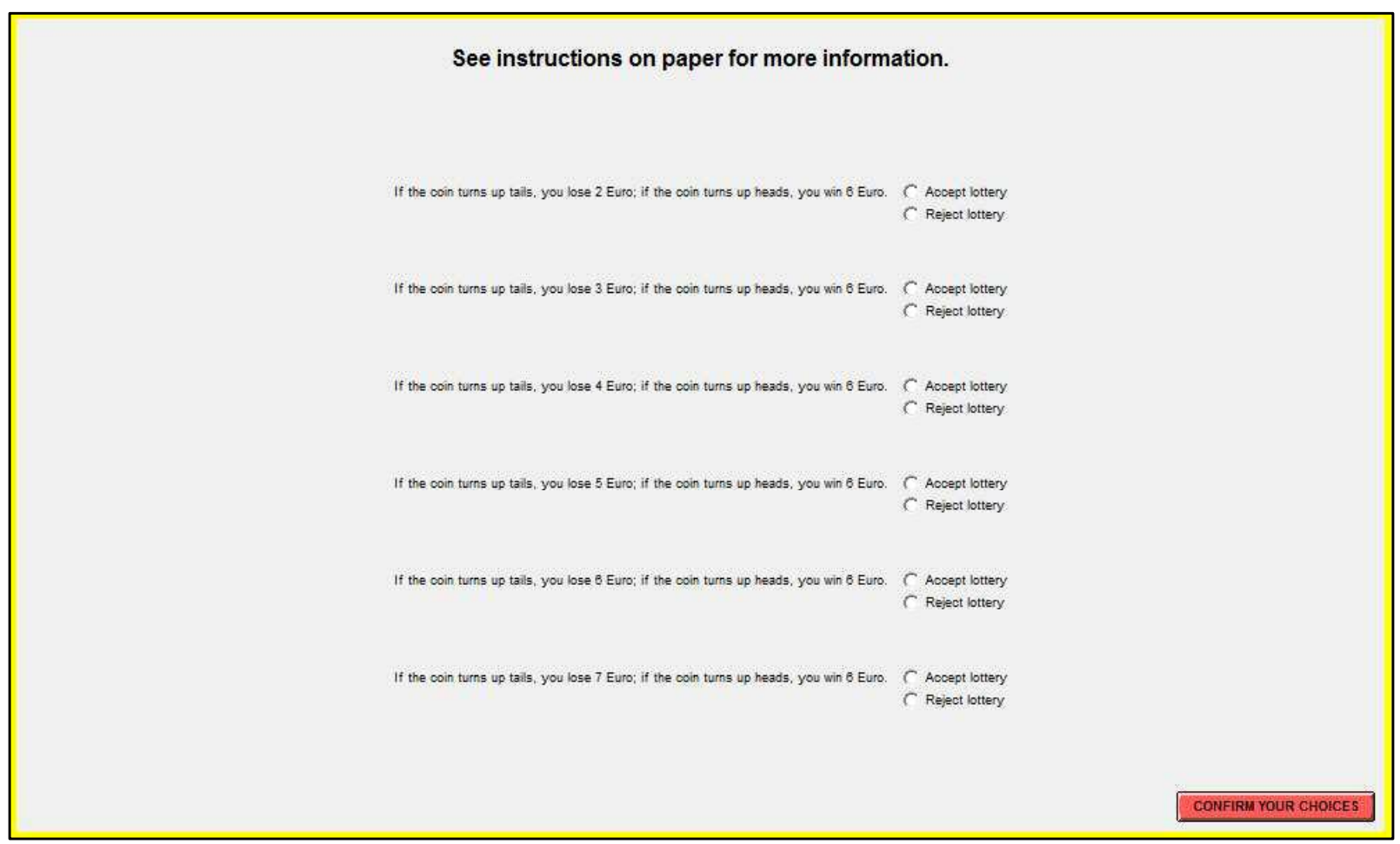


Aligned

Have a look at your screen

You see six lotteries in which you and a randomly drawn participant in this room can win or lose money. For each lottery, YOU have to decide whether you and the other participant accept or reject the lottery.

If you accept the lottery, the computer flips a coin;

- if the coin shows heads, you and the other participant receive 6 Euros in addition to your participation fee and his/her participation fee, respectively;

- if the coin shows tails, you and the other participant lose a certain amount of your participation fee and his/her participation fee, respectively.

If you reject a lottery, no amount will be added (subtracted) to (from) your and his/her participation fee, respectively.

After you have clicked the button "CONFIRM YOUR CHOICES", the computer randomly picks one of the six lotteries for payoff. If you have chosen to accept this lottery, the computer flips the coin and you and the other participant's payment are determined as indicated on the screen.

However, you will be randomly matched with one other participant in this room. The computer flips another coin to determine whether your decision or the decision of the other participant will be implemented for payment for both of you!

Your payments will be shown after the questionnaire.

See instructions on paper for more information.

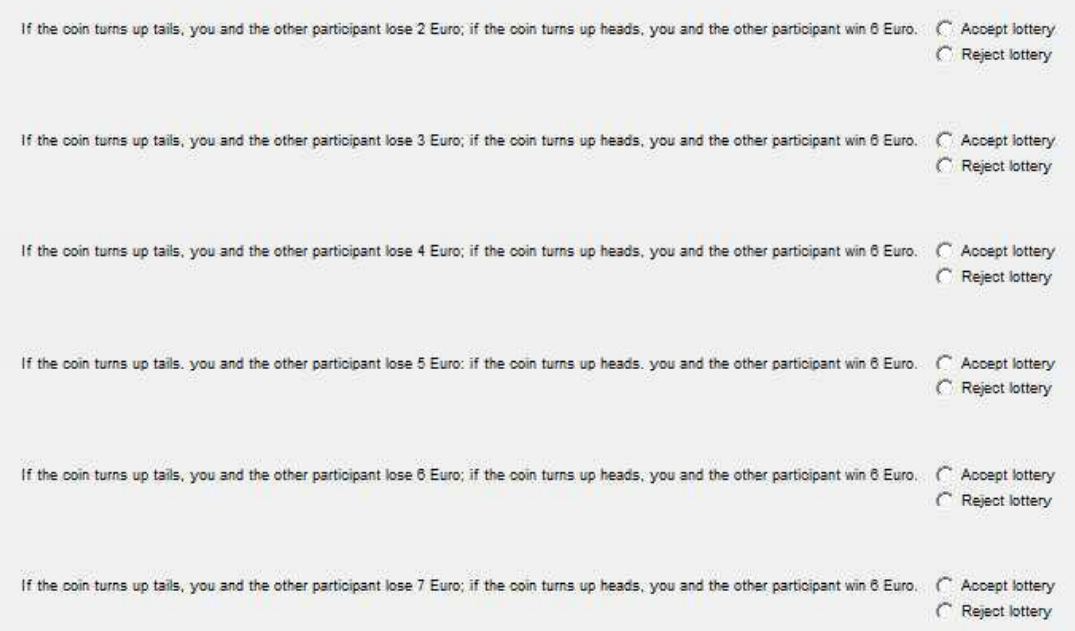


Others

Have a look at your screen

You see six lotteries in which a randomly drawn other participant in this room can win or lose money. For each lottery, YOU have to decide whether the other participant accepts or rejects the lottery.

If you accept the lottery, the computer flips a coin;

- if the coin shows heads, the other participant receives 6 Euros in addition to his/her participation fee;

- if the coin shows tails, the other participant loses a certain amount of his/her participation fee.

If you reject a lottery, no amount will be added (subtracted) to (from) his/her participation fee.

After you have clicked the button "CONFIRM YOUR CHOICES", the computer randomly picks one of the six lotteries for payoff. If you have chosen to accept this lottery, the computer flips the coin and the other participant's payment are determined as indicated on the screen.

While you decide on the lottery for a randomly drawn participant in this room, a different randomly drawn participant in this room will decide for you!

Your payments will be shown after the questionnaire.

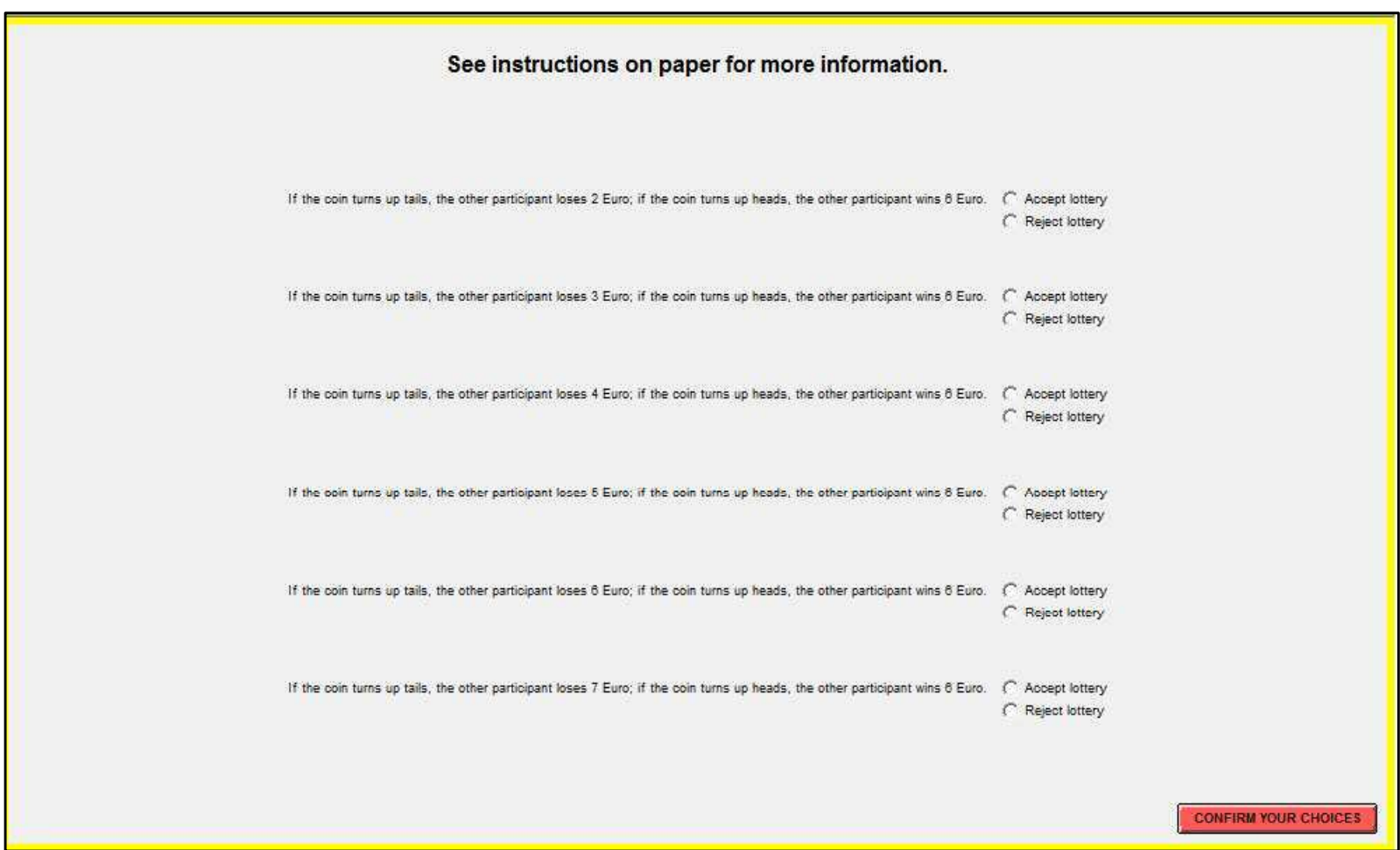

